\title{
O estudo da sílaba na fonologia auto-segmental
}

\author{
Delson Biondo \\ Universidade Federal do Paraná
}

\section{Abstract}

The present paper summarizes the fundamental principles of the syllable structure analysis proposed by Goldsmith (1990), on the basis of autosegmental phonology. According to this approach, sonority principle, licensing, directionality of syllable structure creation, maximal onset principle and syllable structure assignement are taken as universal laws that regulate a suitable syllable formation. Portuguese words are used to exempllfy function and application of some of these principles. 
$\mathrm{E}$ $m$ linhas gerais, podemos dizer que a fonologia auto-segmental, tal como proposta por Goldsmith (1990), postula fundamentalmente o seguinte: a existência de uma representação subjacente para cada forma a ser analisada; níveis hierarquicamente distribuídos; princípios gerais que atuam autonomamente em cada nível e regras particulares, selecionadas e ativadas diferentemente pelas línguas.

Segundo a teoria, o caminho que uma forma subjacente percorre até atingir a sua forma de superfície é chamado de processc de derivação. Para que uma estrutura seja bem-formada num certo nível, ela deve obedecer a todos os princípios que atuam naquele nível, caso contrário será rejeitada como uma estrutura malformada. O nível que interessa diretamente ao estudo da estrutura silábica é o nível da palavra (ou nível P). Nele, a silabificação serve como uma condição de boa-formação sobre as representações.

Portanto, a expectativa fundamental da fonologia auto-segmental em relação ao estudo da sílaba é estabelecer os princípios universais que funcionem como condições necessárias, no nível $\mathrm{P}$, para a silabificação básica. Isso não significa, entretanto, que esses princípios possam prever todas as formas finais das sílabas de todas as línguas. Eles apenas se aplicam obrigatoriamente no nível $\mathbf{P}$ para que haja uma silabificação primária, sobre a qual, posteriormente, cada língua aplicará regras particulares até que a derivação atinja a forma de superfície esperada.

Para a fonologia auto-segmental, princípios fortes necessitam ter motivações fortes. As motivações podem ser entendidas, grosso modo, como as evidências linguuísticas ou as descrições estruturais de fenômenos lingüísticos nas mais diversas línguas que, de certa forma, estimulam o estabelecimento de algumas generalizações sobre os fenômenos. 
E importante observar que o salto da observação para a generalização envolve, obviamente, a formulação de hipóteses arrojadas por parte dos fonologistas. A escolha de uma ou outra hipótese dependerá, muitas vezes, da quantidade de informação que se tem sobre o assunto, da quantidade de fenômenos que a hipótese explica, da quantidade de regras particulares adicionais exigidas ou da complexidade do aparato teórico utilizado.

A principal motivação que a fonologia auto-segmental tem para propor uma estrutura interna básica para a sílaba é o fato de esta ser descrita tradicionalmente (cf. Malmberg, 1955) como um agrupamento de vogais e consoantes que formam um constituinte fonológico composto de três subpartes: (i) uma cadeia de zero ou mais consoantes, (ii) um segmento vocálico e (iii) uma cadeia mais curta de zero ou mais consoantes. Chamaremos a primeira parte de "onset", a segunda de núcleo e a terceira de cauda. O núcleo é sempre uma posição obrigatória e, segundo a hipótese mais forte, tem apenas uma única posição disponível, ao contrário do "onset" e da cauda.

De acordo com uma outra motivação conhecida (cf. Câmara Jr., 1979), as línguas fazem uma distinção binária de peso silábico responsável, principalmente, pelas regras de atribuição de acento. Se tomarmos as posições de núcleo e cauda como ramificações mais profundas de um nódulo que chamaremos de rima, podemos dizer que sílabas leves (ou livres: a (sa), pé, bri (lho)) são as que têm na rima apenas a posição de núcleo e sílabas pesadas, (ou travadas: par, mel, ai (po), ban (co), os (tra)) as que têm a rima desdobrada em núcleo e cauda.

A estrutura interna básica hierarquizada da sílada é, portanto, a seguinte:

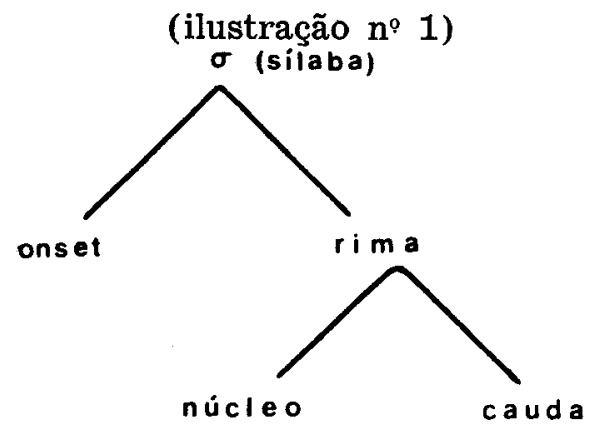


A teoria prevê também que esta estrutura está organizada somente sobre a camada CV (consoantes e vogais), ou seja, cada posição disponível na árvore silábica se associa a uma ou mais posições da camada CV. A quantidade de segmentos que podem se associar às posições da sílaba ou a ordem em que eles podem aparecer devem-se, principalmente, a restrições refletidas pelo princípio de sonoridade juntamente com as condições particulares de licenciamento silábico em cada língua.

Para Bloomfield (1933), a sonoridade inerente de cada um dos segmentos podia predizer a ordem em que eles apareceriam dentro do "onset" e da cauda. Essa idéia foi a responsável pela formulação de um princípio que estipula o seguinte: as sílabas tendem a ser construídas a partir de um crescendo de sonoridade até alcançarem o pico sonoro e procederem, então, ao diminuendo de sonoridade. $O$ esquema abaixo representa este princípio:

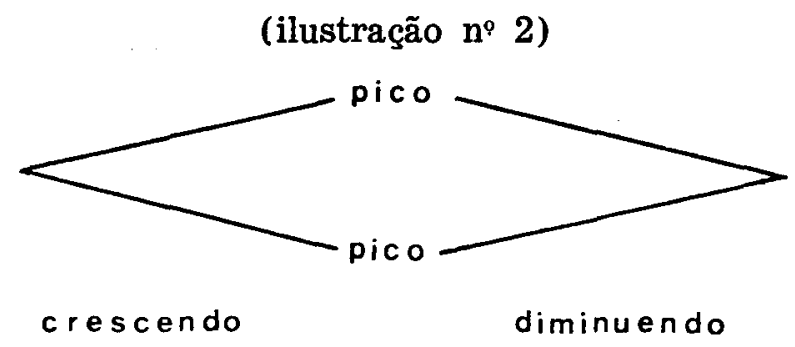

Se entendermos a sonoridade como uma escala que reflete $\circ$ grau de abertura do aparelho vocal durante a produção dos sons ou a quantidade de energia produzida durante o som, podemos estabelecer a seguinte hierarquia de sonoridade entre os elementos:

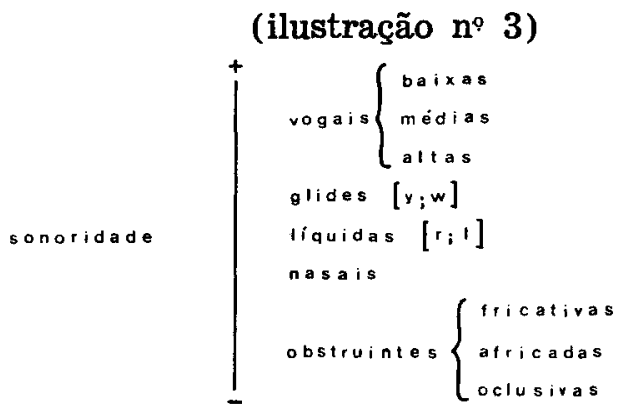


De acordo com essa escala, os elementos [ + sonoros] poderão ocupar a posição de núcleo e os elementos [- sonoros], as posições periféricas. Algumas tentativas têm sido feitas no sentido de restringir ainda mais esse princípio, pois, tal como está formulado, permite sílabas que não são jamais encontradas e exclui sílabas perfeitamente possíveis em certas línguas (Malmberg, 1955). E provável que este princípio seja universal e se desdobre em parâmetros (ainda não totalmente conhecidos) que envolvem a fixação da distância mínima e máxima de sonoridade permissível entre os segmentos em cada uma das línguas.

O licenciamento silábico é outro princípio que se relaciona com a estrutura interna da sílaba. Segundo ele, todo auto-segmento ou conjunto de traços fonológicos de uma língua deve receber uma autorização dos licenciadores silábicos no nível $P$ para que possam ser realizados foneticamente, caso contrário serão apagados. O nó silábico ( $\sigma$ ) é o principal licenciador da sílaba; a cauda e certos morfemas de final de palavra (-th do inglês, por exemplo) são considerados licenciadores secundários. Ainda de acordo com a teoria, todo licenciador, dotado pela gramática da língua da habilidade de autorizar o aparecimento de auto-segmentos, não pode autorizar mais do que uma ocorrência do auto-segmento em questão para uma mesma posição do nódulo.

A essência da idéia de licenciamento é tentar explicar e prever a diversidade de contrastes existentes no "onset" e na cauda de diferentes línguas. Ela se apóia em motivações fortes como, por exemplo, o fato de que os sistemas fonológicos conhecidos têm a tendência de considerar as posições de "onset" e de núcleo como um único domínio, contando como uma única unidade de tempo (mora) quando se trata de aplicar regras de acento ou quando se trata de fazer associações de tom. Além disso, observou-se que, neste domínio combinado de "onset" e núcleo, um traço fonologicamente distintivo é especificado apenas uma única vez. Por exemplo: o traço [labial] autorizado pelo nó silábico principal $(\sigma)$ impede que um $/ \mathrm{p} /$ ou um $/ \mathrm{b} /$ precedam uma glide $/ \mathrm{w} /$ no "onset" silábico, pois tanto esta como aqueles necessitariam do mesmo traço duas vezes dentro do mesmo domínio.

Sabe-se também que, quando há caudas, elas geralmente contam como uma única unidade, à parte, e sempre têm possibilidades de autorização reduzidas. Em todas as línguas que permitem cauda 
há muito poucos contrastes disponíveis nessa posição e os que estão disponíveis são um subconjunto dos contrastes fonológicos possíveis no primeiro domínio ("onset" e núcleo).

De acordo com a teoria, os traços fonologicamente distintivos de uma língua devem ser todos postos (sem redundância) em chaves embaixo dos licenciadores e autorizados em forma de comandos (ou flechas) que associam os traços às posições em que eles podem aparecer:

FIGURA 1

O princípio do licenciamento numa análise esquemática da primeira silaba da palavra "pampa"

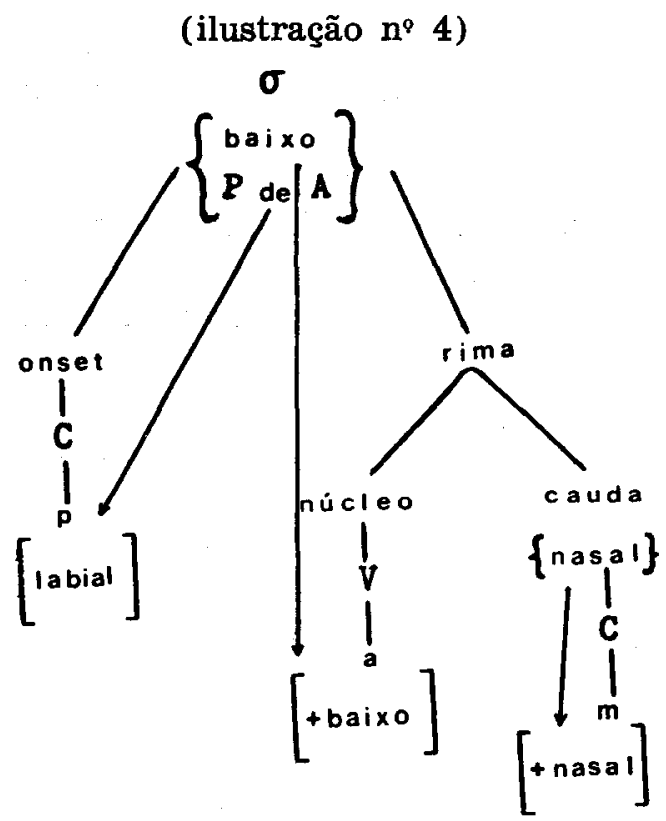

$P$ de A significa "ponto de articulação" - uma nomenclatura tradicional de classificação articulatória que, embora corresponda a vários traços, segundo o sistema de Chomsky e Halle (Martins, 1988), conta como uma unidade apenas para os propósitos de licenciamento -; conforme Goldsmith (1990), o licenciador principal só poderá comandá-lo uma única vez para o "onset" e uma única vez para o núcleo. 
Esta breve introdução sobre a estrutura interna da sílaba é suficiente para que possamos descrever a silabificação, entendida como um processo que associa uma cadeia linear de segmentos a uma estrutura silábica.

Um enfoque mais tradicional diria que cada segmento deve pertencer a pelo menos uma sílaba, porém, sabe-se que há línguas que permitem o aparecimento de material "extra-silábico", ou seja, material segmental presente no final de uma palavra que não pode ser silabificado de acordo com os princípios que se mantêm no interior da palavra (o árabe e o inglês são línguas desse tipo).

Há, pelo menos, três procedimentos possíveis para se construir a silaba. Dois deles (o primeiro e o segundo) admitem a presença de material extra-silábico e todos os três observam o caráter obrigatório do núcleo da sílaba.

O primeiro procedimento de silabificação (exemplo 1) toma a forma subjacente a ser derivada, identifica os seus segmentos vocálicos, atribuindo-lhes os nós de rima $(R)$ e de sílaba $(\sigma)$, e só então começa a juntar consoantes ao núcleo $(\mathrm{N})$, de maneira a obedecer ao padrão silábico da língua.

exemplo 1: língua portuguesa

padrão silábico: (C) (C) V (C) (C)

forma subjacente: $\mathrm{p} \mathrm{l}$ a $\mathrm{n}$ a $1 \mathrm{t} \mathrm{us}$ forma de superfície: /p I a $\mathrm{n}$ a $\mathrm{w}$ t $\mathrm{u}$ s/

(ilustração $\mathrm{n}^{\circ}$ 5)

(a)

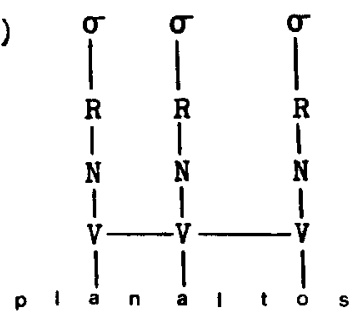

(b)

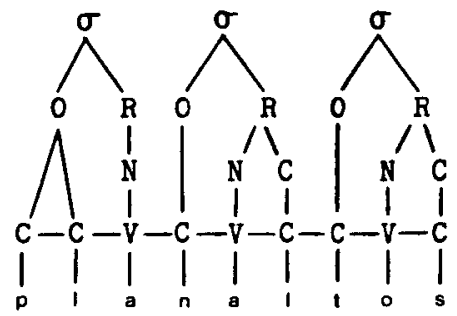


O segundo procedimento, também denominado de "exploração linear", toma a forma subjacente e aplica o padrão silábico da língua, construindo sílabas linearmente, da direita para a esquerda ou da esquerda para a direita, de modo a construir o menor número possível de sílabas de acordo com as restrições particulares da língua sobre as sílabas possíveis. Os seus resultados são semelhantes, na maioria das vezes, aos do primeiro enfoque.

$O$ terceiro procedimento (exemplo 2), também conhecido por "enfoque de silabificação total", impõe sobre a forma subjacente uma estrutura silábica básica, da direita para a esquerda ou da esquerda para a direita, de modo a construir sílabas com posições vazias quando não houver material segmental disponível para uma posição obrigatória.

\author{
exemplo 2: língua yokuts \\ padrão silábico: $\mathrm{CV}(\mathrm{X}) \rightarrow \mathrm{CV}, \mathrm{CVV}$ ou CVC \\ forma subjacente: logw - hin \\ forma de superfície: /logiw - hin/
}

(ilustração $\mathrm{n}^{9}$ 6)

(a) da esquerda para a direita
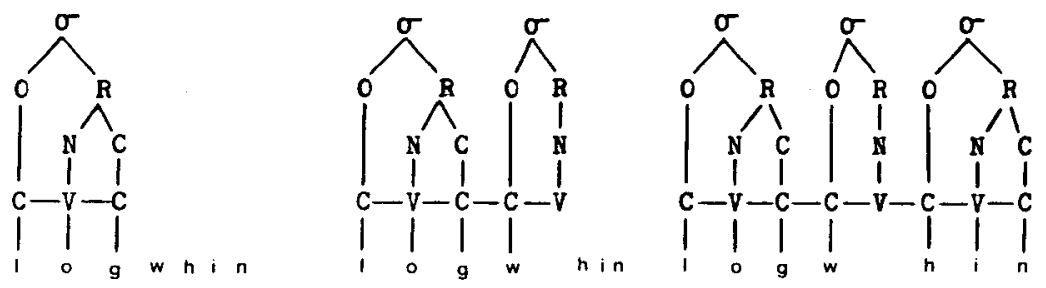

(b) da direita para a esquerda
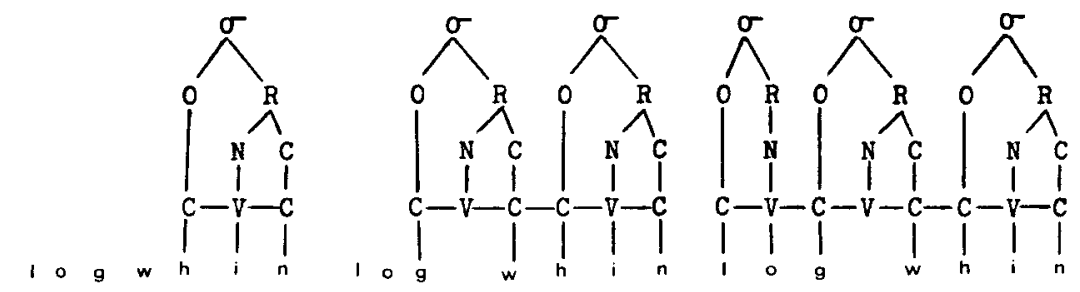
No exemplo 2 (a) e (b), estão em jogo dois princípios da teoria: o da direcionalidade da criação de estrutura silábica e o princípio do "onset" máximo. Este último estabelece o seguinte: ao se construir uma sílaba, é mais importante que ela tenha um "onset" do que uma cauda, em outras palavras, uma sílaba se constrói com o menor número possível de licenciadores. O núcleo e o "onset" contam como um só licenciador, enquanto que a presença de uma cauda conta como um licenciador a mais, violando assim o princípio do "onset" máximo. Portanto, seqüências do tipo CVCV estariam mal-formadas em (i) e bem-formadas em (ii) :

\section{(ilustração $\mathrm{n}^{0} 7$ )}

(i)

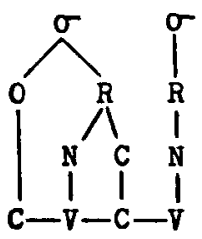

(i1)

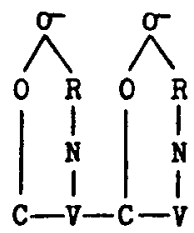

(estrutura com 3 licenciadores) (estrutura com 2 licenciadores)

Já o princípio da direcionalidade nos diz que, no yokuts (Goldsmith, 1990), as sílabas devem ser construídas da direita para a esquerda - como mostra o exemplo 2 (b) - uma vez que é a estrutura originada dessa direcionalidade que resultará na forma de superfície correta /logiw - hin/ após a inserção de uma vogal epentética /i/ na posição vazia de núcleo da sílaba medial. A atribuição de estrutura silábica da esquerda para a direita nos daria uma forma de superfície incorreta ${ }^{*}$ logwi-hin.

No português, embora não haja estudos que nos indiquem como funcionam esses princípios, podemos especular sobre a direcionalidade mais favorável analisando as adaptações sofridas por vocábulos emprestados de outras línguas, que geralmente são forçados a respeitar as restrições silábicas do português. Observe a análise esquemática abaixo: 
exemplo 3: língua portuguesa

padrão silábico: (C) (C) V (C) (C)

forma subjacente: $\mathrm{s} n \boldsymbol{D} \mathrm{b}$

forma de superfície: / $\mathrm{z} n \rho \mathrm{b}$ i/

(ilustração $n^{9} 8$ )

(a) da esquerda para a direita
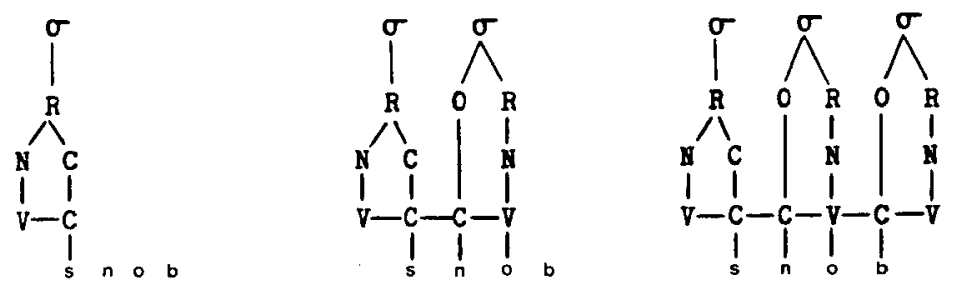

(b) da direita para a esquerda
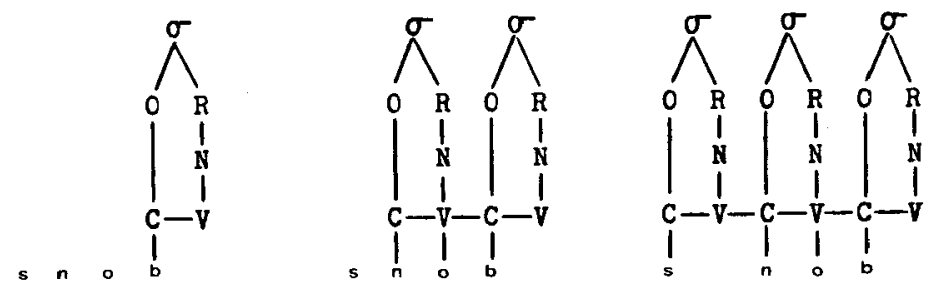

O exemplo 3 (a) nos indicaria que, no português, as sílabas devem, provavelmente, ser construídas da esquerda para a direita, uma vez que a estrutura originada dessa direcionalidade nos dará a forma de superfície correta da palavra "esnobe" após a regra de epêntese. A atribuição de estrutura silábica da direita para a esquerda sugere uma forma de superfície incorreta $* / s$ i n $\rho$ b i/. Essa análise, mesmo problemática - pois depende de uma exposição clara sobre o princípio do "onset" máximo no português - pode ter fundamento se levarmos em conta que o termo snooker do inglês pode gerar, conforme a direcionalidade escolhida, "esnúquer" ou "sinuca". 
O princípio da direcionalidade, embora sendo de extrema importância para o segundo e terceiro procedimentos de silabificação, ainda não está satisfatoriamente explicado. O principal problema é que a escolha da direção é geralmente guiada pelo fenômeno da epêntese (processo que insere uma vogal numa posição vazia de núcleo). Entretanto, há línguas em que a posição vazia recebe outro tipo de tratamento (ou o apagamento definitivo da posição ou uma associação desta com duas posições na camada CV, dando origem a um segmento alongado). A despeito das controvérsias sobre o assunto, a teoria fonológica auto-segmental trabalha com a hipótese da universalidade deste princípio.

Todos os três procedimentos de atribuição de estrutura silábica têm vantagens e desvantagens, na medida em que fazem previsões corretas sobre certas formas e previsões incorretas sobre outras. Nos casos em que há várias consoantes intervocálicas, deve-se apelar para restrições particulares da língua a fim de se determinar a silabificação correta. Nos casos em que uma posição vazia na estrutura silábica dispara não apenas regras de epêntese, mas também de degeminação ou alongamento de um segmento (como, por exemplo, o turco), deve-se apelar para um ordenamento das regras. O importante é que a fonologia auto-segmental chama a atenção para o fato de que a silabificação é uma condição de boaformação imposta no nível $P$ e que precisa, portanto, ser sempre observada. Primeiramente, porque uma silabificação imprópria expõe os problemas para a fonologia, geralmente na forma de material não-silabificável que deve sofrer processos de adaptação distintos em cada língua. E, em segundo lugar, porque após a resolução desses problemas a silabificação (total ou própria) deve ser outra vez obedecida para que a derivação tenha sucesso (cf. exemplo 4).

exemplo 4: língua portuguesa

padrão silábico: (C) (C) V (C) (C)

forma subjacente: $\mathrm{p} n$ e $\mathrm{w}$

forma de superficie: /p i n e w/

(a) silabificação imprópria 


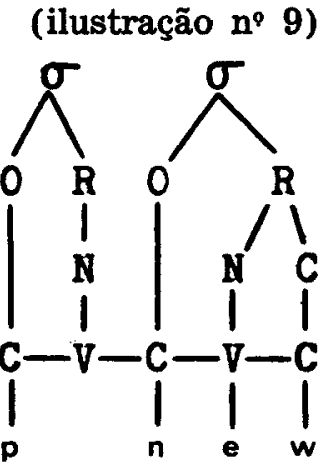

Regra de Epêntese: $\quad \varnothing \rightarrow\left\{\begin{array}{l}\mathrm{i} \\ \mathrm{e}\end{array}\right\} / \mathrm{C}^{\prime}-$

$\emptyset$ : o elemento ausente na camada segmental.

$\left\{\begin{array}{l}\mathrm{i} \\ \mathrm{e}\end{array}\right\}$ : escolha dependente do dialeto.

C': segmento extra-silábico (geralmente consoantes, em estado de limbo durante o processo de silabificação, esperando uma sílaba).

(b) silabificação após a aplicação da regra de epêntese.

(ilustração $\mathrm{n}^{\circ}$ 10)

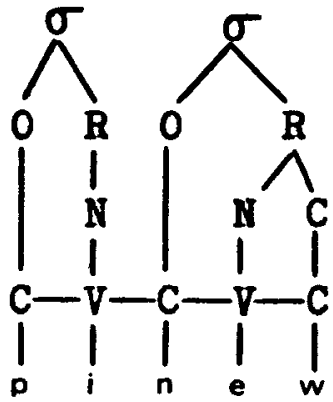

Neste ponto, algumas revisões teóricas são necessárias. Temos tratado a silabicidade como uma propriedade inerente da camada CV. A questão, agora, é saber se a silabicidade não seria uma propriedade estrutural do núcleo silábico. Em outros termos: a distinção 
dos segmentos em dois blocos (vocálicos e não-vocálicos) é dada numa camada autônoma ou seria determinada pela posição que estes segmentos ocupam na estrutura silábica? A fonologia auto-segmental considera correta a segunda hipótese e propõe a seguinte modificação: eliminar o traço [silábico] da camada CV, transformando-a numa camada de unidades de tempo ou Camada $\mathrm{X}$, na qual todos os elementos são idênticos e intercambiáveis, sendo que é a posição na árvore da sílaba associada a elementos da camada $X$ que informa sobre a qualidade silábica desses elementos (vogal, quando associado ao núcleo; consoante, quando associado ao "onset" ou à cauda). De acordo com essa reformulação, o contraste entre vogais e glides desaparece. Teremos, na verdade, um mesmo elemento, transcrito como $/ u /$, se estiver associado ao núcleo (i), e, como /w/, se estiver associado ao "onset" (ii) ou à cauda (iii) .

(ilustração $\mathrm{n}^{\circ}$ 11)

(i)

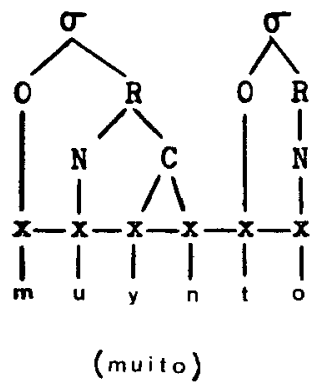

(11)

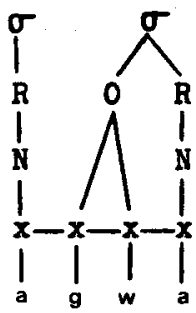

(água ) (11i)

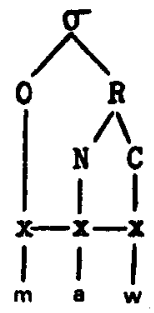

(mau)

A assimetria muito comum entre o "onset" e a cauda é tradicionalmente descrita como restrições particulares das línguas sobre as estruturas possíveis, por exemplo: são comuns restrições que proíbem consoantes na cauda (em línguas CV); restrições que permitem uma consoante no "onset"; restrições sobre a consoante final de sílabas CVC (apenas glides, líquidas, nasais homorgânicas com o “onset” da sílaba seguinte ou /s/) ; etc.

O método da listagem é ainda o procedimento mais comum para se determinar a quantidade de posições permitidas no "onset" e na cauda de uma língua. Através dele, obtemos a fórmula tradicional (C) (C) V (C) (C) que, em princípio, parece dar conta da 
maioria dos padrões silábicos do português (Pontes, 1972; Knies \& Guimarães, 1989) - entretanto, dependendo do tratamento que dispensarmos aos ditongos (especialmente os crescentes, que em português podem ser silabificados como hiatos) e à nasalidade, palavras como "pátria" (três posições no "onset" /pa-tria/) e "mães" (três posições na cauda /mayns/) ocasionarão o aumento dos padrões silábicos e, consequientemente, uma revisão na fórmula acima. Suponhamos, porém, que o máximo de apenas duas posições sejam permitidas no "onset" e na cauda do português, necessitaríamos ainda estabelecer qual é o centro (head) e quais são os satélites de ambos os nódulos. O centro é aquela posição obrigatória que será ocupada quando existir apenas um segmento disponível no "onset" ou na cauda. Os satélites são as posições que não necessitam ser preenchidas ou que podem ser facilmente apagadas.

Não há estudos do português analisando a estrutura silábica a partir desses pressupostos. Em inglês, a estrutura silábica tem, segundo a hipótese mais aceita, a seguinte configuração:

\section{(ilustração $n^{\circ}$ 12)}

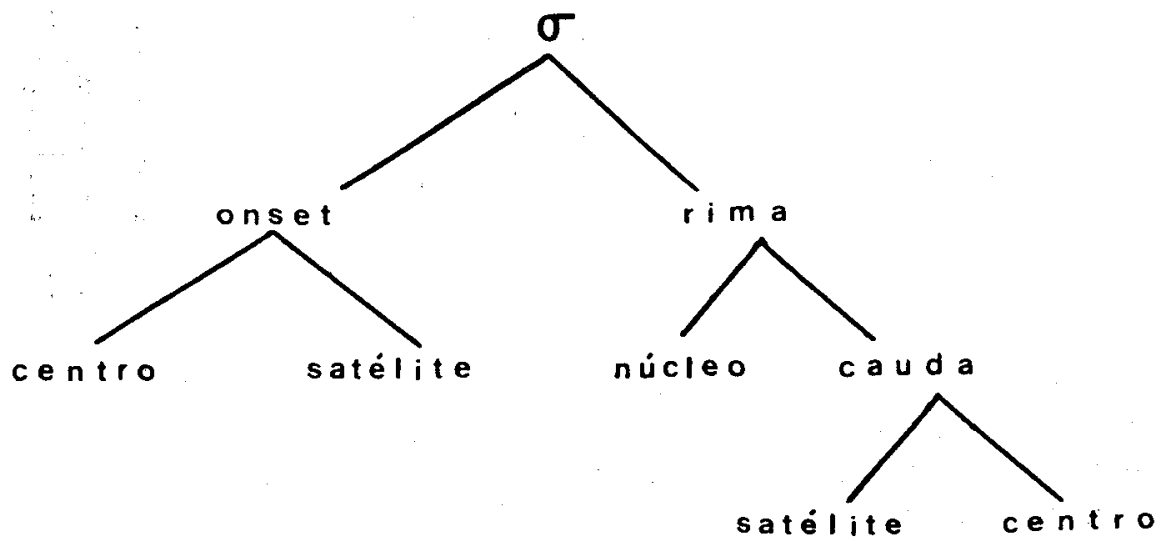

Uma análise auto-segmental da sílaba no português envolve, portanto, o tratamento de temas mais específicos, como: a delimitação dos traços fonologicamente distintivos da língua (evitando-se a redundância e optando-se por uma análise que melhor explique a ditongação, a nasalação, a estrutura interna da sílaba, etc.), bem como um inventário bastante amplo das proibições particulares do português sobre o "onset" e a cauda para transformá-las em licen- 
ciamento silábico. Somente de posse dessas informações é possível analisar e discutir melhor os princípios tomados pela fonologia auto-segmental como supostamente universais.

Segundo Goldsmith (1990), a partir de 1980 a sílaba não pôde mais ser desprezada pela teoria fonológica. $\overline{\mathbf{A}}$ medida que uma série de fenômenos iam sendo estudados ou reanalisados, ficava cada vez mais claro o vínculo entre a sílaba e os processos fonológicos.

Sabe-se, por exemplo, que as regras segmentais podem ser sensíveis à estrutura silábica conforme sejam condicionadas: (i) a se aplicar a um segmento quando a estrutura da sílaba em que ele se encontra satisfizer uma certa condição; (ii) a se aplicar a um segmento quando este estiver num lugar específico da sílaba ou (iii) a se aplicar nos contextos que não podem ser claramente silabificados. Da mesma forma, sabe-se que as regras prosódicas envolvendo tom e acento prestam especial atenção à estrutura siłábica das palavras.

São estas e outras evidências que justificam e motivam o desenvolvimento do aparato teórico utilizado pela fonologia autosegmental para estudar a sílaba e outros fenômenos a ela vinculados.

\section{REFERENCLAS BIBLIOGRAFICAS}

BLOOMFTELD, L. Language. New York: Henry Holt, 1933.

CAMARA, Jr., J. M. História e estrutura da lingua portuguesa. 2* ed. Rlo de Janeiro: Padrão, 1976.

GOLDSMITH, J.A. Autosegmental and metrical phonology. Oxford: Brasll Blackwell, 1990.

KNIES, C. B. \& GUIMARAES, A.M. Elementos de fonologia e ortografia do português. Porto Alegre: Ed. UFRGS, 1989.

MALMBeRG, B. A fonética. Lisboa: Livros do Brasil. 1954. p. 115-122.

MARTINS, M. R. D. Ouvir falar: introđução à fonética do português. Lisboa: Caminho, 1988. p. 105-118.

PONTES, Eunice. Estrutura do verbo no portugues coloquial. Petrópolis: Vozes, 1972. p. 22-30.

SCHANE, S. A. Generative phonology. New Jersey: Prentice-Hall, 1973. 